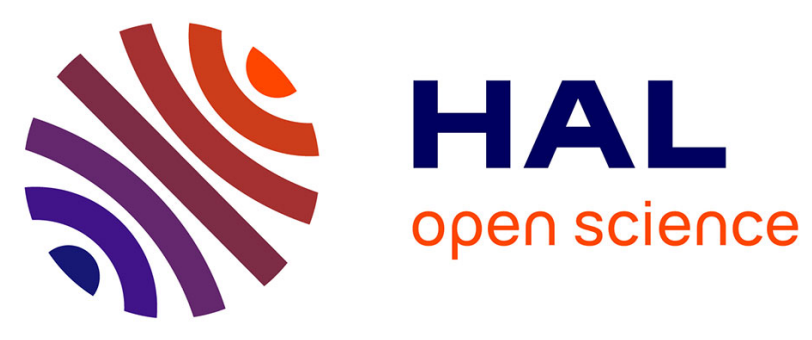

\title{
Dynamic Acoustic Evidence of Nasalization as a Compensatory Mechanism for Voicing in Spanish Apraxic Speech
}

Anna K Marczyk, Yohann Meynadier, Yulia Gaydina, Maria-Josep Solé

\section{To cite this version:}

Anna K Marczyk, Yohann Meynadier, Yulia Gaydina, Maria-Josep Solé. Dynamic Acoustic Evidence of Nasalization as a Compensatory Mechanism for Voicing in Spanish Apraxic Speech. Fang Q.; Dang J.; Perrier P.; Wei J.; Wang L; Yan N. Studies on Speech Production. 11th International Seminar, ISSP 2017, Tianjin, China, October 16-19, 2017, Revised Selected Papers, 10733, Springer International Publishing, pp.225-236, 2018, Lecture Notes in Artificial Intelligence, 978-3-030-00125-4. 10.1007/978-3-030-00126-1_20 . hal-01979546

\section{HAL Id: hal-01979546 https://hal.science/hal-01979546}

Submitted on 13 Jan 2019

HAL is a multi-disciplinary open access archive for the deposit and dissemination of scientific research documents, whether they are published or not. The documents may come from teaching and research institutions in France or abroad, or from public or private research centers.
L'archive ouverte pluridisciplinaire HAL, est destinée au dépôt et à la diffusion de documents scientifiques de niveau recherche, publiés ou non, émanant des établissements d'enseignement et de recherche français ou étrangers, des laboratoires publics ou privés. 


\title{
Dynamic acoustic evidence of nasalization as compensatory mechanism for voicing in Spanish apraxic speech
}

\author{
Anna K. Marczyk ${ }^{1,2[0000-0001-5183-2956]}$, Yohann Meynadier², Yulia Gaydina² and Maria- \\ Josep Solé $3[0000-0002-2752-8767]$ \\ ${ }^{1}$ Brain and Language Research Institute, 5 av. Pasteur, 13100 Aix-en-Provence, France \\ ${ }^{2}$ Aix-Marseille Université, CNRS, LPL, Aix-en-Provence, France \\ ${ }^{3}$ Universitat Autònoma de Barcelona, Spain \\ anna.marczyk@lpl-aix.fr
}

\begin{abstract}
This paper is concerned with the phonetic realization of the voicing contrast by two Spanish speakers with surgery-related apraxia of speech and two matched control speakers. Specifically, it examines whether speakers with AOS, widely reported to have a deficit in laryngeal control, use nasal leak as a compensatory mechanism aimed at facilitating the initiation of voicing in word-initial stops. The results show that the two apraxic speakers produced prevoicing in $/ \mathrm{b}$ $\mathrm{d} \mathrm{g} /$ in only one third of the cases (correctly identified as 'voiced'). In these cases, however, they exhibited significantly longer prevoicing than control subjects, and this a longer voiced portion was closely related to a longer nasal murmur. These results shed light on the compensation strategies used by apraxic subjects to achieve voicing. Differences in the intensity patterns of nasal and voiced stops indicate that apraxic speakers control the timing of velopharyngeal gesture, suggesting that apraxia is a selective impairment.
\end{abstract}

Keywords: Nasality, Voicing, Apraxia of speech, Acoustics.

\section{Introduction}

Apraxia of speech (AOS) is a motor speech disorder of neurological origin that selectively affects phonetic encoding processes [1-4] and results in distortions of the sound shape of words. Phonetic investigations of apraxic speech have yielded evidence for impaired laryngeal control, timing and coordination with supralaryngeal articulators [5]. This deficit results in frequent devoicing errors, a hallmark of AOS across languages, especially in phrase- or word-initial consonants. The initiation of voicing, however, is difficult not only for speech-impaired speakers. Indeed, aerodynamic conditions for phrase-initial stops may require additional motor adjustments to favor voicing. In 
'true voicing'1 languages, such as Spanish, nasal leakage has been reported to be a common facilitatory mechanism associated with voicing initiation and maintenance [6]. Nasal leak helps to evacuate the air behind an oral closure and maintain the transglottal pressure differential necessary to initiate glottal pulsing. In this paper, we seek to determine whether two Spanish speakers with AOS use this strategy to enhance voicing perception and analyze how their phonetic implementation differs from that of healthy speakers.

Articulatorily, nasality involves synchronizing the velic movement with the oral release. The difference between nasals and prenasalized voiced stops lies in the fact that the velic closure occurs almost simultaneously to the oral release in nasals and before the oral release in prenasalized stops. These differences are captured by acoustic metrics of duration and amplitude [7,8]. Thus, in this paper we will combine analyses in the temporal and intensity domains.

The synchronization of articulatory events may be problematic for speakers with apraxia. Yet, while difficulties in the coordination of the laryngeal and oral gestures have been widely reported, the phonetic realization of nasal consonants is relatively unimpaired [9]. We hypothesize that apraxic subjects may employ nasal leak to promote voicing and we predict that, when an initial voiced stop is successfully produced, analyses will reveal acoustic traces of compensatory activity (e.g., a longer nasal murmur during the consonant closure).

While the mechanism described above may prove useful to initiate voicing in stop consonants, apraxic speakers must finely control the timing of velopharyngeal closure and thus avoid productions that fall into the 'nasal' category. Our analyses aim at comparing nasals and voiced stops to determine whether there are differences in their phonetic realization between control and apraxic speakers.

Our ultimate goal is to gain a better understanding of how the timing deficit in apraxia may affect the phonetic realization of voiced stops involving prenasalization.

\section{Methodology}

\subsection{Participants}

Two Spanish female speakers aged 34 and 37, both right-handed, diagnosed with apraxia of speech related to high-grade glioma resection, and two matched controls took part in this study. The tumors were revealed by epileptic seizures and transient expressive aphasia. A pre-surgical fMRI assessment showed scarce bilateral activation during

\footnotetext{
${ }^{1}$ It is well-known that Spanish /b d g/ are typically produced with voicing lead ('pre-voicing') such that the onset of vocal fold vibration precedes the release of the stop, resulting in negative VOT values, while $/ \mathrm{p} \mathrm{t} \mathrm{k/} \mathrm{are} \mathrm{produced} \mathrm{with} \mathrm{a} \mathrm{near-simultaneous} \mathrm{release} \mathrm{and} \mathrm{onset} \mathrm{of} \mathrm{laryngeal}$ vibration, resulting in VOT values that are approximately zero [10, 11]. Voiceless stops are phonetically realized as stops, i.e., with a complete oral closure, in all contexts. By contrast, voiced /b d g/ are realized as stops utterance-initially, after a nasal, or after [1] in the case of $/ d /$, and systematically realized as approximants in all other contexts, for example, between vowels or after a continuant.
} 
language tasks with a strong left laterization of the expressive language functions, primarily involving the pars opercularis area of the inferior frontal gyrus (BA44) and the premotor cortex, for both patients. For speaker 1 the growing tumor mass induced a displacement and deformation of the anterior segment of the left arcuate fasciculus. Both patients underwent an awake craniotomy guided by direct brain-mapping. The lesions were well-circumscribed and restricted to the cortical area with little infiltration. Initially mute, both patients underwent intensive speech therapy and evolved from an acute stage towards Broca's-type aphasia and, finally, apraxia of speech. Clinical assessment 12 months post-surgery revealed no deficit in naming, auditory comprehension, reading, writing or repetition abilities, apraxia of speech being the only postoperative symptom at the time of testing. Their speech was characteristically slow and slurred, with syllable-by syllable articulation, frequent phonetic distortions and errors surfacing as phoneme substitutions, especially devoicing of word-initial stops. Overall these symptoms were compatible with those observed in the stroke-related AOS.

\section{$2.2 \quad$ Stimuli}

Acoustic data were obtained for isolated words elicited in word reading and repetition tasks. We used material compiled for a larger study on the phonetic realization of Spanish consonants [12], from which we selected bi- and tri-syllabic words with word-initial

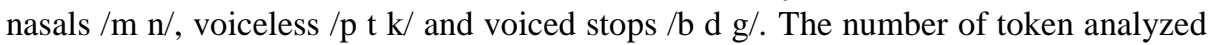
included 22 nasals, 296 voiceless stops and 251 voiced stops for each participant. The consonants of interest were always followed by a non-high vowel /e a o/.

\subsection{Analysis procedure}

Recordings of the elicited consonant productions were independently transcribed by two phoneticians and classified as on-target nasals, voiceless stops, voiced stops, or errors (i.e., 'voiced stops' identified as 'voiceless'). No instances of voiced stops heard (i.e., transcribed) as nasals were found. Voiced stops were also categorized as 'prenasalized' if they exhibited nasal murmur, a weak formant structure and increased amplitude of voicing on the acoustic records.

Because our data were limited to acoustic output only, it was not straightforward to infer whether nasal leak had occurred and, if so, whether or not it was used in combination with other adjustments aimed at maintaining a low oral pressure for voicing such as cavity enlargement. Nonetheless, the acoustic records obtained showed that prevoiced /b d g / in Spanish could present (i) a strong low frequency resonance at about $200-250 \mathrm{~Hz}$ which is the main resonance of the nasal cavity, and (ii) a weak formant structure that resembled vowel formants, with large antiresonances caused by the interaction between oral and nasal cavity resonances. These realizations were considered to involve nasal leak and are illustrated in Fig. 1 for control and apraxic speakers. 

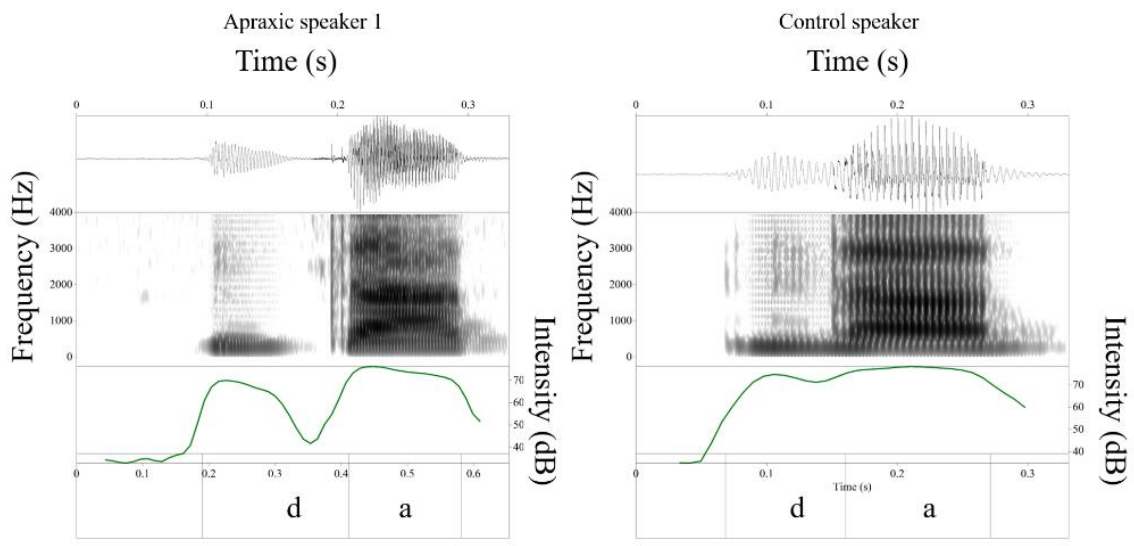

Figure 1. Waveform, spectrogram $(0-5 \mathrm{kHz})$ and amplitude $(\mathrm{dB})$ of the syllable /'da/ in the word dato ('information') produced by a control (right) and an apraxic speaker (left), showing voicing and prenasalization.

Furthermore, we obtained aerodynamic data for the same control and apraxic subjects for larger corpus with the EVA2 data acquisition system [13]. The aerodynamic data revealed that nasal leak exhibited the acoustic characteristics described above. This is illustrated in Fig. 2, which shows nasal leak throughout the stop closure for utteranceinitial $/ \mathrm{b} /$ and the acoustic result. Thus we feel confident that nasal leak may be inferred from the acoustic signal.

Analyses in the temporal domain. Three acoustic parameters were measured: voicing lead, voicing lag and nasal murmur duration during stop closure. For VOT analysis, in cases where periodicity was uninterrupted from the onset of glottal pulsing to the noise burst generated at the constriction (whether due to passive tissue expansion only or its co-occurrence with nasal leak), it was measured as negative VOT (Fig. 1, right). If voicing was initiated but ceased after a few tens of ms (passive devoicing), presumably due to failure to maintain nasal leak, two measurements were made. First, as per the revisited definition of VOT [14], such cases were regarded as negative VOT. However, given that the duration of devoicing can be informative of underlying pathological processes, the second set of measurements considered each element separately: voiced portion with nasal murmur, devoiced portion and positive VOT (Fig. 1, left). Analyses were carried out by means of linear regression intended to detect differing patterns in the distribution of these parameters between control and apraxic subjects. 


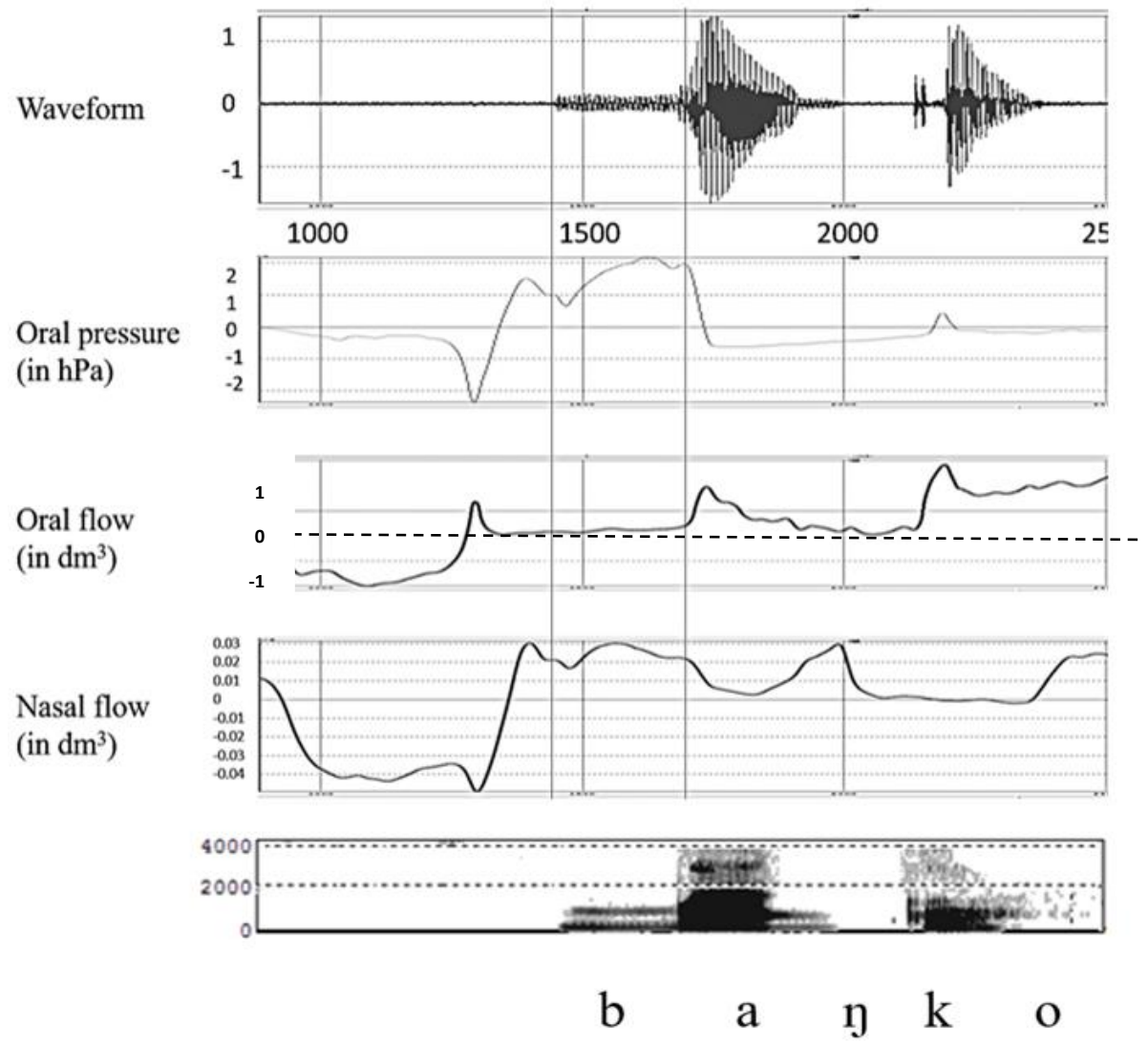

Figure 2. Waveform, intraoral pressure, oral flow, nasal flow and spectrogram $(0-4 \mathrm{KHz})$ for Spanish banco ('bank') by an apraxic speaker. In the oral flow channel, the level of no airflow $\left(0 \mathrm{dm}^{3}\right)$ is indicated by a dashed line. Long vertical lines mark onset of voicing and stop release.

Analyses in the intensity domain. Visual inspection of the intensity contours showed that data points constituting the intensity trajectories tended to display a curvilinear shape (Fig. 1). Using Praat [15], we extracted the intensity listing at every 0.01 seconds for every nasal, voiced and voiceless stop. In order to adjust for variation in segment duration, temporal normalization was applied throughout the process (i.e., the time coordinate was always between 0 and 1 ).

The curve fitting procedure was then applied using the cubic polynomial equation

$$
y(x)=a \times 3+b x 2+c x+d
$$

where $y$ corresponds to the intensity value (in $\mathrm{dB}$ ) and $x$ to a point in time, in order to transform the data into a set of four coefficients, each of them carrying information relative to different aspects of the curve. The estimated coefficients were saved as variables for statistical analyses. 
Our first hypothesis predicted differences in intensity values ( $y$ ) between nasals and voiced stops across groups. Since the coefficient $d$ corresponds to the intensity value at consonant onset (if $x=0$, all the other coefficients are set to 0 and $y$ equals $d$ ), it was entered as the dependent variable in a linear regression mixed model with phonemic category, group and their interaction as predictors, and items as a random factor.

The second linear regression mixed model was aimed at testing the hypothesis relative to differences in intensity dynamics across phonemic categories (nasals vs. voiced stops) and groups (apraxic vs. control), specifically the falling and rising intensity patterns in voiced stops with nasal leak, which correspond to prenasalization, subsequent passive devoicing and burst release. This difference is expressed through the covariance pattern between the leading coefficients of the cubic polynomial $a$ and $b$. Hence, the second model included the coefficient $a$ as the outcome variable and a three-way interaction between phonemic category, group and the covariate $b$ as a predictor, as well as items as the random intercept.

Finally, to support the results of the model above, we calculated the roots and vertices of the derivative of the cubic function. The roots represent the inflection points of intensity curve oscillations, that is, onset and offset of falling/rising slopes. Vertices represent intensity values $(y)$ at these points in time. Roots and vertices were calculated for the intensity profile of each category using functions available in the rootSolve package in $\mathrm{R}$ [16]. The intensity profile denotes a contour that represents a given phonemic category, obtained by averaging each of the coefficients of the polynomial expression (see Fig. 6 in the Results section). The roots and vertices will provide information about the values of increase or decrease in amplitude (in $\mathrm{dB}$ ) and the exact timing of these modulations during consonant closure.

\section{$3 \quad$ Results}

\subsection{Identification and temporal results}

Figure 3 shows the results of the identification results for apraxic productions. Intended voiceless stops were correctly identified as voiceless in all cases. By contrast, $71 \%$ (n $=178$ ) of the intended voiced stops produced by the speakers with AOS were identified as voiceless (error) and only $29 \%(\mathrm{n}=73)$ were correctly perceived as voiced. Comparison of the identification and acoustic data revealed that voiced stops heard as voiceless displayed short positive VOT values whereas correctly identified voiced stops showed prevoicing. There was no significant difference in VOT values between ontarget voiceless stops and voiced stops identified as voiceless (errors) $\left[\mathrm{F}_{(1)}=.7, \mathrm{p}=\right.$ .400; $\mathrm{M}=27 \mathrm{~ms}(\mathrm{SE}=1.44)$ for voiceless vs. $\mathrm{M}=29 \mathrm{~ms}(\mathrm{SE}=1.89)$ for voiced stops]. In the control group, voiceless stops were always correctly identified and only six wordinitial /b d g / (2.4\%) were identified as devoiced (error). 


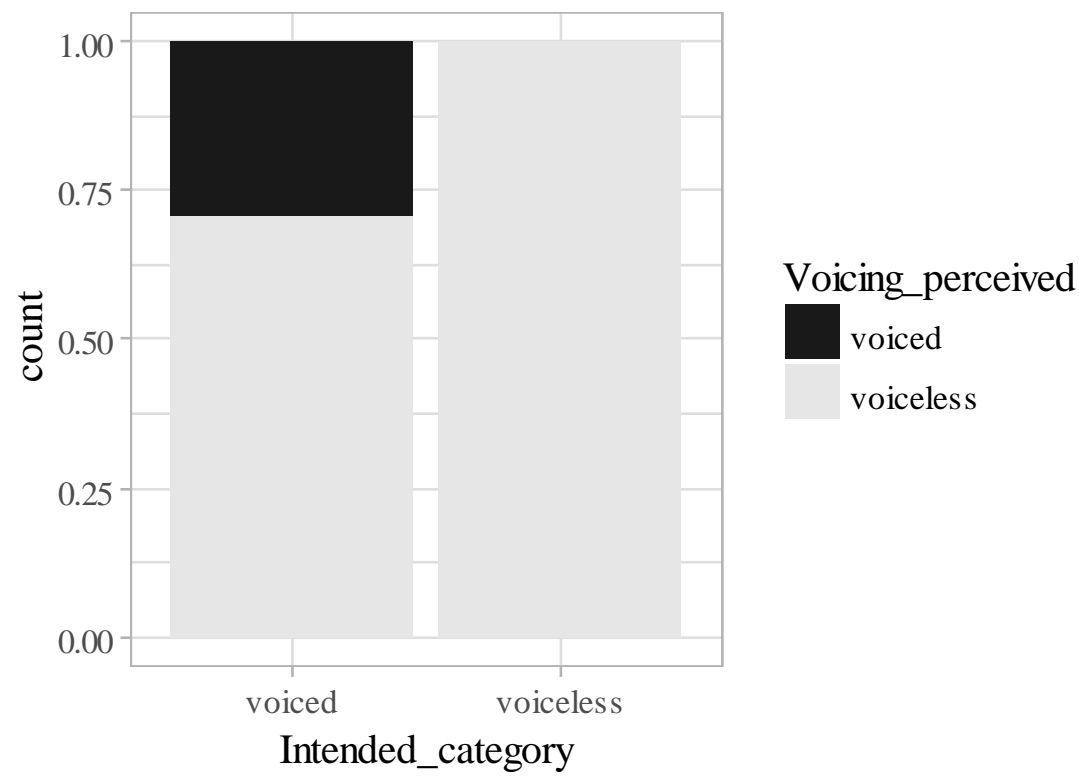

Figure 3. Relative frequencies of intended word-initial voiced and voiceless stops produced by apraxic speakers, as perceived by listeners. Voiceless stops, $n=296$; voiced stops, $n=251$.

Turning to temporal parameters, the first set of analyses was aimed at comparing VOT values for apraxic and control speakers in correctly perceived productions to identify potential compensatory mechanisms in the former. For correctly identified voiced and voiceless stops, the analyses revealed a significant main effect of phonemic category (voiced vs. voiceless) $\left[\mathrm{F}_{(1)}=2038, \mathrm{p}=.000\right]$, no significant effect of group, and a significant interaction between phonemic category and group $\left[\mathrm{F}_{(1)}=325.34, \mathrm{p}=.000\right]$, indicating differences in the phonetic implementation of voicing across populations. As shown in Fig. 4, this difference was due to voiced stops, which showed significantly longer voicing lead in apraxic speech as compared to the speech of healthy controls [M $=-177 \mathrm{~ms}(\mathrm{SE}=4.75)$ vs. $\mathrm{M}=-67 \mathrm{~ms}(\mathrm{SE}=5.11)]$. 


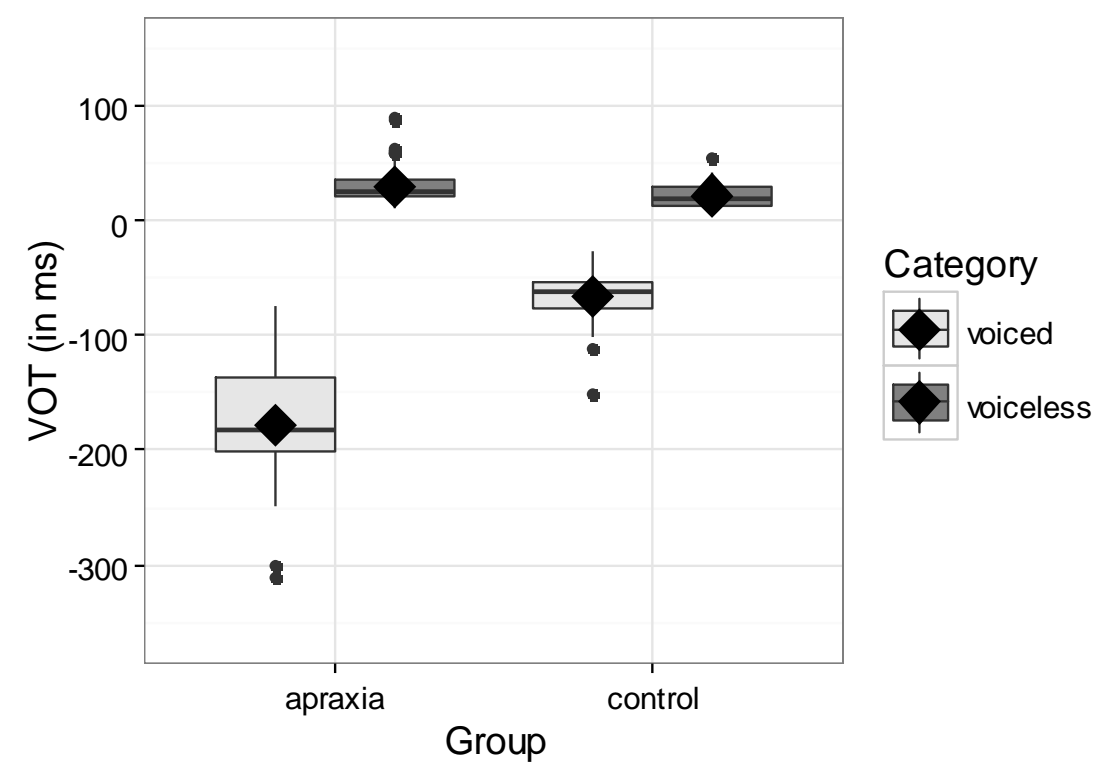

Figure 4. Distribution of VOT values for correctly identified voiced and voiceless stops in AOS and control groups.

Further analyses, limited to correctly identified voiced stops in the apraxic group, showed that tokens classified as prenasalized (48 cases out of 73) exhibited overall 28 $\mathrm{ms}$ longer voicing lead than voiced stops without nasal leak $[\mathrm{M}=-179 \mathrm{~ms}(\mathrm{SE}=10)$ vs. $M=-151 \mathrm{~ms}(\mathrm{SE}=16)$, respectively]. The longer voicing lead in apraxic speakers may be the result of a motor adjustment involving a longer velic opening gesture. It must be noted that no nasal murmur was observed for initial voiceless stops in either of the groups.

With respect to passive devoicing, a devoiced portion was observed in the apraxic group only, in 19 out of 73 realizations of on-target voiced stops. A linear regression was performed to determine whether there was a significant difference between the two apraxic speakers. The results showed that the mean duration of the devoiced portion was longer in one of the speakers (speaker 2), as illustrated in the left-hand graph in Fig. $5[\mathrm{M}=7.43 \mathrm{~ms}(\mathrm{SE}=3.91)$ for speaker 1 and $\mathrm{M}=43.70 \mathrm{~ms}(\mathrm{SE}=6.66)$ for speaker $\left.2, \mathrm{~F}_{(1)}=22.54, \mathrm{p}=.000\right]$. These results are in line with what can be seen in the righthand graph, which shows the duration of nasal murmur. Here we see a significantly longer prenasalized (voiced) portion for the first speaker with apraxia $[\mathrm{M}=167.17 \mathrm{~ms}$ $(\mathrm{SE}=8.43)]$ than for the second $\left[\mathrm{M}=110.10 \mathrm{~ms}(\mathrm{SE}=15.36), \mathrm{F}_{(1)}=11.75, \mathrm{p}=.001\right]$. Thus the results indicate that, in the apraxic speakers, a shorter devoiced portion is closely related to a longer nasal murmur. 

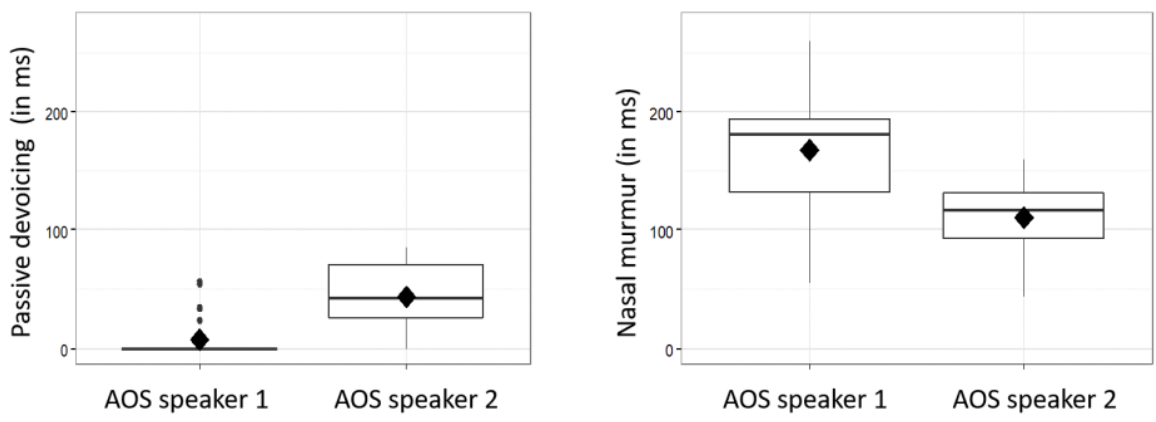

Figure 5. Distribution of passive devoicing (left) and nasal murmur for the two apraxic speakers.

\subsection{Intensity results}

The results for intensity were subjected to analysis in order to look for differences in the intensity envelope across groups and phonemic categories in accordance with our initial hypotheses. A linear regression analysis of intensity values at consonant onset showed a significant effect of phonemic category $\left[\mathrm{F}_{(1)}=30.62, \mathrm{p}=.000\right]$ and group $\left[\mathrm{F}_{(1)}\right.$ $=40.14, \mathrm{p}=.000]$ but no significant interaction effects. Nasals showed overall higher intensity at consonant onset than voiced stops, as predicted by our hypothesis $[\mathrm{M}=64$ $\mathrm{dB}(\mathrm{SE}=1.09)$ for nasals vs. $\mathrm{M}=58 \mathrm{~dB}$ ( $\mathrm{SE}=.56$ ) for voiced stops]. This was true for both the control and the apraxic group in spite of the fact that the apraxic speakers exhibited overall lower intensity in voiced stops and nasal productions [M $=59 \mathrm{~dB}$ (SE $=.88)$ as compared to the control group $(\mathrm{M}=64 \mathrm{~dB}(\mathrm{SE}=.85)]$.

In line with our predictions, the analyses of co-variance of the leading coefficients as a function of group and phonemic category showed a significant three-way interaction $\left[\mathrm{F}_{(1)}=4.35, \mathrm{p}=.037\right]$. Post-hoc analyses indicated that while the covariance pattern between the coefficients $a$ and $b$ did not vary significantly between groups (apraxic vs. control) for nasal stops, it displayed significantly different slopes for voiced stops $[\beta=$ $-.11, \mathrm{SE}=.02, \mathrm{p}=.000]$. The significant difference in the intensity contour of wordinitial voiced stops in apraxic and control speakers may reflect different patterns of prenasalization.

The intensity contour profiles fitted with cubic polynomial equations are illustrated in Fig. 6. The results of our analyses of intensity oscillations can be summarized as follows. Lack of multiple roots of the derivative function in the control speakers (bottom graphs in Fig. 6) suggests that there is no change in the slope direction for any of the phonemic categories (although the growth rate may vary across time). Results for the apraxic group (top graphs) show that nasal stops exhibit a similar pattern across speakers with a slight drop in intensity $(1 \mathrm{~dB})$ at half the closure. For voiced stops, this decline is greater $(2-4 \mathrm{~dB})$ and occurs earlier. These results are provided in Table 1 and illustrated in Fig. 6. 
AOS speaker 1

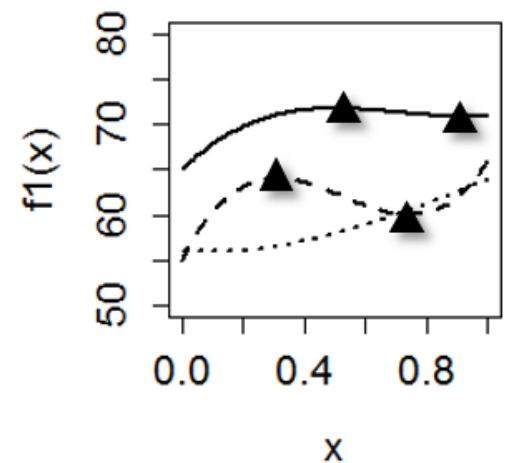

control speaker 1

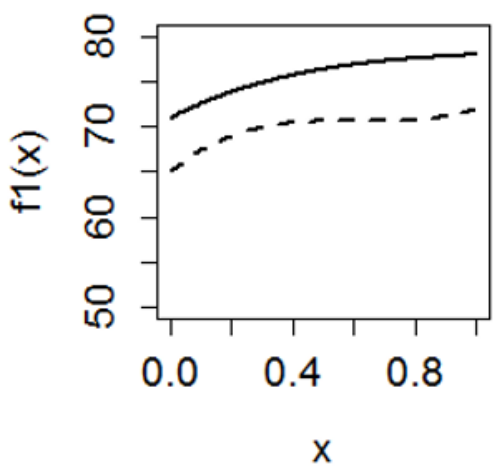

AOS speaker 2

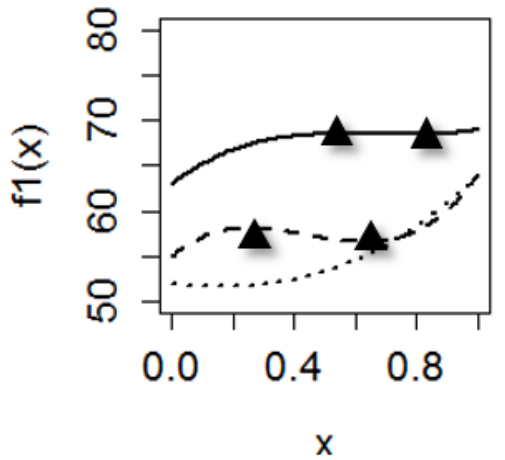

control speaker 2

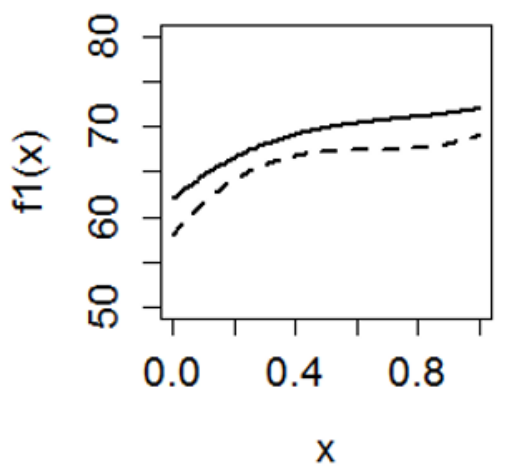

Figure 6. Intensity profiles fitted with a three-term polynomial equation for two apraxic (top) and two control speakers (bottom). Solid lines: nasals; dashed lines: voiced stops; dotted lines (for apraxic subjects only): stops identified as errors. Triangles represent vertices/roots.

Table 1. Summary of the results for intensity oscillation analyses. $x^{1}$ and $x^{2}$ represent roots of the function, $\operatorname{diff}(\mathrm{dB})$ represents the intensity values at $x^{I}$ and $x^{2}$ (i.e., vertices of the function).

\begin{tabular}{|c|c|c|c|c|}
\hline & $\begin{array}{c}\text { phonemic } \\
\text { category }\end{array}$ & $\boldsymbol{x}^{\mathbf{1}}$ & $\boldsymbol{x}^{\mathbf{2}}$ & $\operatorname{diff(dB)}$ \\
\hline \multirow{2}{*}{ AOS speaker 1 } & nasal & 0.5 & 0.9 & $72-71$ \\
\cline { 2 - 5 } & voiced stop & 0.3 & 0.7 & $64-60$ \\
\hline \multirow{2}{*}{ AOS speaker 2 } & nasal & 0.5 & 0.8 & $69-68$ \\
\cline { 2 - 5 } & voiced stop & 0.2 & 0.6 & $58-56$ \\
\hline Control speakers & \multicolumn{4}{|c|}{ *no multiple roots } \\
\hline
\end{tabular}




\section{Discussion and conclusion}

This study provides preliminary evidence for the use of motor adjustments - in this case prenasalization - to initiate voicing by speakers with a neurologically-based speech disorder. Our results show that when two apraxic speakers attempted to produce Spanish /b d g/ the resulting output showed prevoicing, and was perceived as 'voiced', only about a third of the time. These productions differed from those in control subjects in that they exhibited significantly longer prevoicing (Fig. 4). The results also showed that for both apraxic speakers a shorter devoiced portion was closely related to a longer nasal murmur (Fig. 5). Taken together, these data give us an idea of strategies used by apraxic subjects to compensate for their voicing deficits.

In sum, our results suggest that nasal leak allows apraxic speakers to initiate and lengthen the voicing lead in word-initial voiced stops, and thus enhance a listener's perception of voicing. Moreover, they show that voicing lead duration (negative VOT) may be an important parameter to detect these kind of compensatory mechanisms in apraxic speech in 'true voice' languages. These results also lend support to the claim that apraxic impairment is selective. Differences in the intensity patterns of nasal and voiced stops seem to indicate that apraxic speakers control rather well the velopharyngeal gesture as a function of phonological contrast.

On the other hand, our results suggest that, while apraxic speakers may exhibit prenasalization, they also exhibit disturbed temporal coordination between glottal and supraglottal gestures, as evidenced by both temporal measurements - that is, the presence of a devoiced portion during the consonant closure (widely described in the literature on apraxic speech) — and differences in slopes of the intensity contour. Still, rather than focusing on what apraxic speakers cannot do, it may be of equal interest to investigate what they can do, as well as examine the interplay between the deficit and the strategies that can be deployed to bypass it. Along these lines, our understanding of 'compensation' is similar to the definition by Simmons-Mackie and Damico [17] as any adaptive behavior that has the following characteristics: (i) it is purposeful and goal-oriented, (ii) it occurs as novel or functionally expanded behavior, (iii) it is context-sensitive and (iv) it is specific to the speaker.

Finally, the observations reported here add new evidence to the existing body of descriptions of symptoms associated with apraxia of speech. While devoicing errors in AOS have been frequently studied, especially in relation to the origin of these errors along the stages of phonetic and phonemic encoding processes, to our best knowledge this is the first study that addresses the interaction between nasal and laryngeal gestures in this disorder. Moreover, studies on surgery-related speech disorders are scarce. Severe cognitive, aphasic or apraxic impairments in such etiologies (as opposed to stroke) are relatively rare, due to the fact that a slow-growing tumor allows the cognitive function to reorganize [18-22]. In the case of the patients studied in this paper, moderate impairment persisted a year after surgery.

Given its limitations, this work should be regarded as merely a preliminary exploration. Future analyses need to include a larger number of speakers, for example, or incorporate not just acoustic but also aerodynamic data. It would also be of considerable interest to make comparisons across languages that use different ranges of VOT. Such 
research would help us to build a truly complete understanding of the production patterns of voiced stops and compensatory gestures in apraxia of speech.

\section{Acknowledgements}

We are grateful to Tim Mahrt for his help with R scripting, Thierry Legou for his assistance with polynomial equations $\overline{\bar{z}}$ and María Machuca for her help with data transcription. This research has been supported by grants ANR-11-LABX-0036 (BLRI), ANR-11-IDEX-0001- (A*MIDEX), FFI2013-46354-P and FFI2017-84479-P, Ministry of Science and Innovation, Spain.

\section{References}

1. Ballard, K. J., Granier, J. P., \& Robin, D. A. (2000). Understanding the nature of apraxia of speech: Theory, analysis, and treatment. Aphasiology, 14(10), 969995.

2. Code, C. (1998). Models, theories and heuristics in apraxia of speech. Clinical Linguistics and Phonetics, 12(1), 47-65.

3. Maas, E., Gutiérrez, K., \& Ballard, K. J. (2014). Phonological encoding in apraxia of speech and aphasia. Aphasiology, 28(1), 25-48.

4. Ziegler, W. (2002). Psycholinguistic and motor theories of apraxia of speech. Seminars in Speech and Language, 23, 231-243. http://doi.org/10.1055/s-200235798

5. Blumstein, S. E., Cooper, W. E., Goodglass, H., Statlender, S., \& Gottlieb, J. (1980). Production deficits in aphasia: A voice-onset time analysis. Brain and Language, 9(2), 153-170.

6. Solé, M.-J. (2018). Articulatory adjustments in initial voiced stops in Spanish, French and English. Journal of Phonetics, 66, 217-241.

7. Burton, M., Blumstein, S. E., \& Stevens, K. N. (1992). A phonetic analysis of prenasalized stops in Moru. Journal of Phonetics, 20, 127-142.

8. Kong, E. J., Syrika, A., \& Edwards, J. R. (2012). Voiced stop prenasalization in two dialects of Greek. Journal of Acoustic Society of America, 132(5), 3439-3452.

9. Kurowski, K., Blumstein, S. E., Palumbo, C. L., Waldstein, R., \& Burton, M. (2008). Nasal Consonant Production in Broca's and Wernicke's Aphasics: Speech Deficits and Neuroanatomical Correlates. Brain and Language, 100(3), 262-275.

10. Borzone de Manrique A. and Gurlekian J. 1980. Rasgos acústicos de las consonantes oclusivas españolas. Revista Fonoaudiológica, 26, 326-330.

11. Quilis, A. 1981. Fonética acústica de la lengua española. Madrid: Gredos.

12. Baqué, L., Estrada, M., Nespoulous, J.-L., Le Besnerais, M., Rosas, A., \& Marczyk, A. (2008). Corpus léxico del proyecto COGNIFON. Barcelona: Unpublished internal document.

13. Ghio, A., \& Teston, B. (2004). Evaluation of the acoustic and aerodynamic constraints of a pneumotachograph for speech and voice studies. In International 
Conference on Voice Physiology and Biomechanics, Marseille, 55-58.

14. Abramson, A. S., \& Whalen, D. H. (2017). Voice Onset Time (VOT) at 50: Theoretical and practical issues in measuring voicing distinctions. Journal of Phonetics, 63, 75-86.

15. Boersma, P., \& Weenink, D. (2017). Praat: doing phonetics by computer. Retrieved from http://www.praat.org/

16. Soetaert, K., \& Herman, P. M. J. (2009). A Practical Guide to Ecological Modelling. Using R as a Simulation Platform. New York: Springer.

17. Simmons-Mackie, N., \& Damico, J. S. (1997). Reformulating the definition of compensatory strategies in aphasia. Aphasiology, 11(8), 761-781

18. Davie, G. L., Hutcheson, K. A., Barringer, D. A., Weinberg, J. S., \& Lewin, J. S. (2009). Aphasia in patients after brain tumour resection. Aphasiology, 23(9), 1196-1206.

19. Duffau, H., Capelle, L., Denvil, D., Sichez, N., Gatignol, P., Taillandier, L., ... Van Effenterre, R. (2003). Usefulness of intraoperative electrical subcortical mapping during surgery for low-grade gliomas located within eloquent brain regions: functional results in a consecutive series of 103 patients. Journal of Neurosurgery, 98, 764-778.

20. Ojemann, J., Miller, J., \& Silbergeld, D. (1996). Preserved function in brain invaded by tumor, Neurosurgery, 39, 253-259.

21. Plaza, M., Gatignol, P., Leroy, M., \& Duffau, H. (2009). Speaking without Broca's area after tumor resection. Neurocase, 15(4), 294-310.

22. Satoer, D., Visch-Brink, E., Dirven, C., \& Vincent, A. (2016). Glioma surgery in eloquent areas: can we preserve cognition? Acta Neurochirurgica, 158, 35-50. 